The Future Energy System

\title{
Renewable energy concepts for addressing climate change
}

Climate change is real, is here, and it will not go away unless we do something. Based on current scientific advancements on energy systems, energy options, and understanding of the Earth's feedback mechanism, there is hope that global efforts could help avoid an environmental catastrophe. However, the action plan needs to be global, based on collective approaches, and implementing state-of-the-art science. Professor Michael internationa and Environmental Research in Germany shares his thoughts on the bigger energy picture and proposes actionable approaches important challenge of our life.

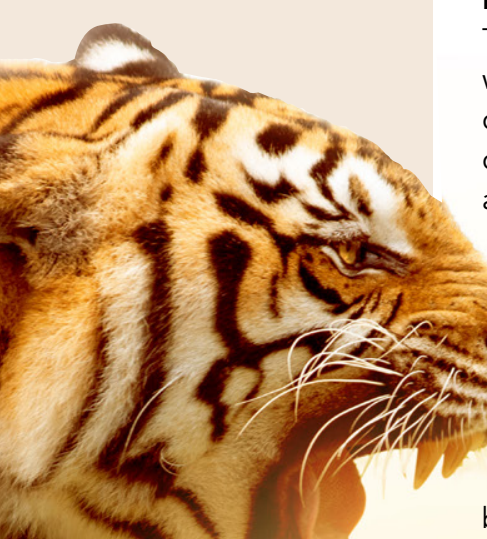

Men asked about the most e, many people might thi of children, PINs, maybe even body measurements. Not many will think of the number which can affect us all in ways that we have heard of, maybe certainly do not want to think about too much. This number is the agreed maximum temperature rise - a mere $2^{\circ} \mathrm{C}$ - the Earth can afford before tipping the scale towards tremendous changes in life as we know it. With our attention being on the hottest and most current topic of all, we elaborate on scientific advancements towards understanding how the Earth responds to climate change, sustainability within the energy sector, and ways that can help delay,

\section{CLIMATE CHANGE AND}

\section{FEEDBACK MECHANISM}

There is an at least vague awareness of

causes, and what needs to be done to

combat it. However, not many people

are aware that the Earth has a feedback echanism, perceiving changes and

'passively' accepting our lifestyle choices. This mechanism shows
a response pattern, with a sharp temperature increase, followed by a less sharp temperature decrease back to the initial level. A known trigger for such a response is the change of solar radiation, and the peak patte mechanisms of the Earth system. mechanisms of the Earth systm. One could argus of the Eath system. One (evel), which suddenly wakes up (sudden temperature increase) due to a trigger, and then it cannot fall back to sleep for

Although it seems that eventually the tiger goes back to sleep (after typically the trigers, as we cannot control solar radiation, but we potentially control other triggers such as greenhouse gas emissions, fossil fuel usage, and land use. Explaining the potential disaster of climate change using the tiger analogy so far (during the last 800,000 years) after each warm, interglacial period the tiger was able to eventually go back to sleep, whereas with anthropogenic triggers we might end up changing the sleeping pattern for the worse. This means that the feedback mechanism can adjust only so much before not being able to stick to the known patter hat the Eart's feedber me is close to giving up on absorbing or choices, are droughts and water scarcity, big population counts not having access to food and medication, the very real possibility of pandemics, and migration of populations from 'well-used' areas to areas which are still able to 'give'.

\section{A NEW ENERGY SYSTEM}

Usually, proposals on how to combat climate change are not being viewed under a global perspective free of political implications, or combined with other, ostensibly unrelated, tangibles of the same problem. For example, there is a tomendous amount of research on topics around water, energy, and aften combined to produce acot

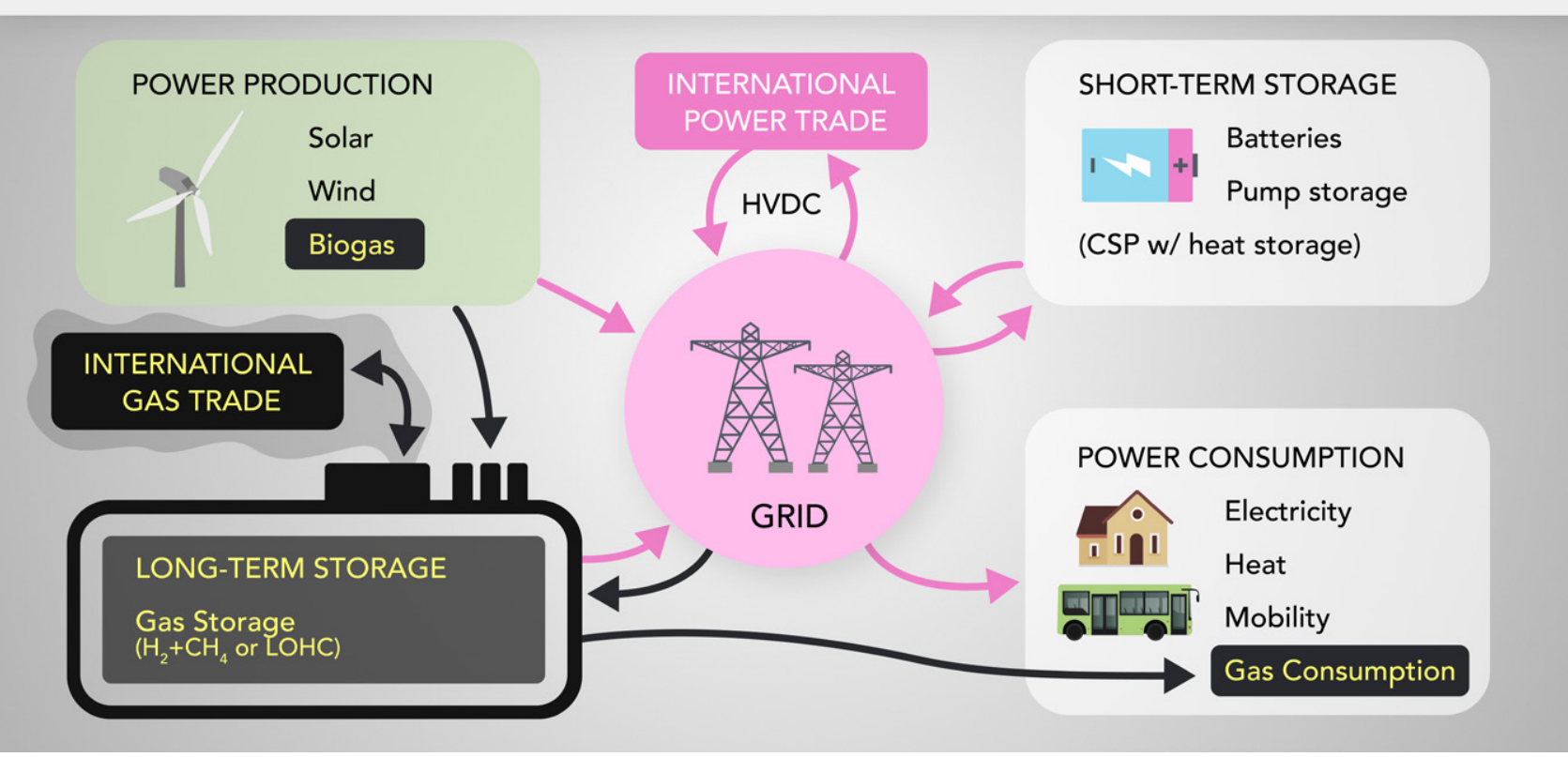

On his YouTube channel (www.youtube.com/watch?v=HXFMZDHPZxc), Prof Düren explains how a renewable energy system might look like in the future. elements are seamlessly combined in the environment. The current energy system towards production of energy to meet anthropogenic demands is unsustainable, as it uses extreme amounts of carbon and water, deranging the natural cycles. Hence, a novel, sustainable energy system should be developed in order to meet our energy demands.

Pivotal towards the development of global, sustainable concepts based on information collected from various Earth's feedback mechanism, focusing on renewable energy solutions toward a necessary energy transition, and implemented on an international leve towards solving the energy problem and creating a peaceful future of the

\section{FROM ENERGY PRODUCTION}

\section{TO STORAGE}

The pillars of Prof Düren's approach for sustainable future evolve around energy

production, energy consumption, energy

Energy demand and consumption varying in different parts of the world within an order of magnitude. Energy transport can be very costly, especially when accounting for power losses. Investing in a high-voltage direct curren (HVDC) power grid which could combine electricity supplied from various sources can help, as well as having an additiona chemical energy carrier. Making the HVDC power grid international would be a great step towards a global effort to energy transition, as countries which Michael Düren

Jiebig University

in Giessen,

Germany. Michael

Düren is a particle

physicist, and

current Professor

The Earth has a feedback mechanism, perceiving changes and responding to them instead of 'passively' accepting

where abundant

renewable energy

of experimental our lifestyle choices.

also member of the executive board of the Center for international Development and Environmental Research in Giessen and member of the energy group at the German Physical Society. He co-founded the DESERTEC foundation in 2008, an initiative developed by scientists, pollicians and economists, aiming to develop a sustainable future. Recently bigger picture of energy, explaining the

three main energy sources, fossil fuels, nuclear energy, and renewable energy. The majority of our energy demands (about $80 \%$ ) is covered by fossil fuels, with renewable energy accounting for with biggest challenge with regards to energy production is increasing the speed of energy production and the volume of produced energy, in order to meet the consumerism and a growing from energy production

inexpensive.

Furthermore, investing in efficiency plans about energy production, transport and consumption could make a big difference in energy associated metrics per sector, season ass county.

After production, consumption, and transport, hhe next key issue is energy storage, which might be either efficient but expicient In or exs oxpensive but not as efrient. Intead ' excluding energy enough', we shoud focus on idertifing 


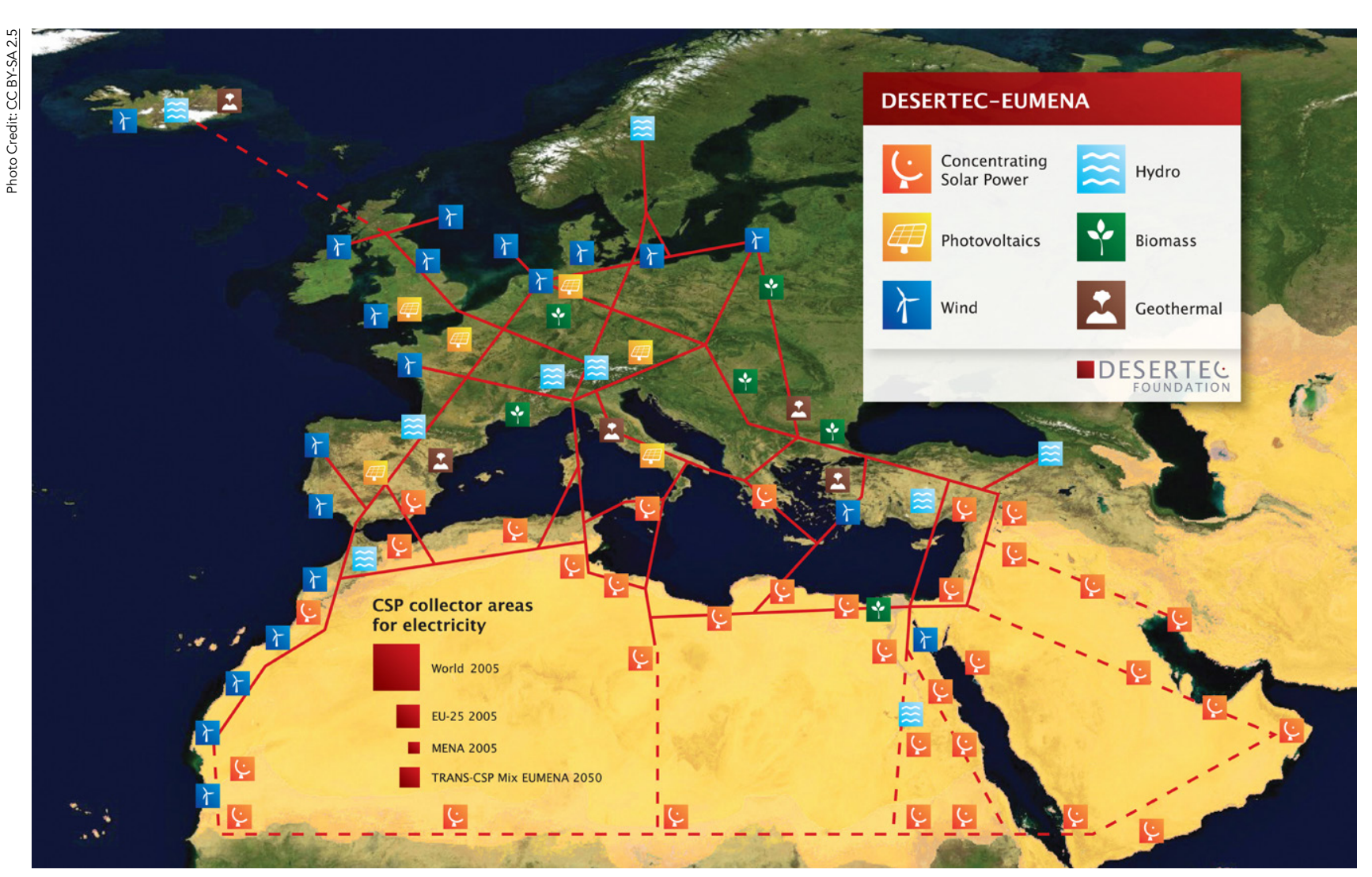

The DESERTEC map: Renewable energies should be generated where the production is the most cost effective. $\begin{aligned} & \text { the best option combination from both } \\ & \text { categories, aiming for short-term and Düren's book also discusses the } \\ & \text { available options for maintaining the }\end{aligned}$ categories, aiming for short-term and long-term storage, in an effort to cover the year-round energy requirements.

\section{RENEWABLE ENERGY:}

WHAT, HOW, WHO

Towards a more sustainable future, the energy sector should stop relying so heavily on fossil fuels and instead explore the untapped potential of renewable energy. There are several
forms of trustworthy renewable energy availability of fresh water supplies. He gives insight and examples with a futuristic approach on water collection and storage, ways to save and recycl water, how to 'make' water from humidity, and

BLACK CARBON SEOUESTRATION IS THE NEW BLACK

Within the proposed global approach

transition towards a

Moving to a sustainable future does not only mean moving forward, but also cleaning up the existing mess.

options, such as exploiting solar power,
wind power, the power of oceans, wind power, the power of oceans, and geothermal power. Furthermore, there are mature technologies which could be easily populated in selected locations, according to their key strengths. For example, solar power could be harvested from a sunny desert, whereas wind power could be produced in the wind belts of renewable energy and sustainability, could not be missing from fue point of moving to a sustaniche forward, but also cleaning up the existing mess. A great example is to be achieved through reforestaton, use of organic construction materials, and black carbon sequestration. Shedding oin forces to fight for keeping the tiger's

\section{Behind the Research}

\section{Dr Michael Düren}

E: michael.dueren@uni-giessen.de $\quad$ T: +496419933220 W: http://www.uni-giessen.de/dueren light into the latter, Prof Düren explains that the concept of black carbon sequestration could replace the existing efforts for carbon sequestration and storage, as in contrast to carbon dioxide, black carbon does not pose any deadly pyrolysis, basically burning carbonbaring substances in absence of oxygen and results in charcoal, which is a safe form of carbon storage, and syngas, way, even plastic can be transformed to products helpful for the environment and further human use.

\section{A MUCH-NEEDED}

ENERGY TRANSITION

With the Earth's feedback mechanism being on the verge of not providing feedback positive for life as we know it, energy transition is necessary. And with our current technologies, it can be done However, alongside energy transition we need to master mindset transition: Prof Duren's action plan requires countries and continents to put their political interests aside, and individuals to Jisiegard her financial interests, and side effects. This method is based on hydrogen, or at ther used to produce

\section{Research Objectives}

In his book, Prof Düren develops a concept for renewable energy system based on technology that is

\section{Detail}

Prof Dr Michael Düren

Center for international Development and

Environmental Research (ZEU)

and II. Physics Institute

Justus Liebig University Giessen

Heinrich-Buff-Ring 16

35392 Giesse

Germany

Bio

Michael Düren $\left({ }^{\star} 1957\right)$ is a particle physicist and professor for experimental physics at the Justus Liebig University (JLU) in Giessen, Germany. He is member of the executive board of the Center for internation Development and Environmental Research (ZEU) in Giessen und member of the energy group at the German Physical Society (DPG). He co-founded the
DESERTEC foundation in 2008 .

Funding

Center for international Development and

Environmental Research (ZEU)

- Justus Liebig University Giessen

\section{Collaborators}

Prof Düren thanks his late colleague Dr Gerhard Knies, who invented "DESERTEC", for many years of fruitful cooperation, his colleagues from the working group "energy" of the German Physical Society for innumerous pieces of background information and discussions, Decially Prof Dr Gerhard Luther, Prof Dr Christian-friends at the DESERTEC Foundation, Dii, DLR and ZEU. present in the atm carbon

\section{JUSTUS-LIEBIG- 7 UNIVERSITAT GIESSEN}

\section{References}

Düren, M. (2017). Understanding the Bigger Energy Picture - DESERTEC and Beyond. In: Düren, M. (ed.): Springer Briefs in Energy. Springer Nature, Switzerland Available at: https://link.springer.com/book/10.1007\% 2F978-3-319-57966-5

Düren, M. (2013). From Desertec to Desertec 2.0. Capital Finance International. Autumn issue.

Düren, M. (2011). Clean Power from deserts. Green, 1, 263-275.

\section{Personal Response}

What would be a realistic timeline for complete energy transition to renewable sources, given political implications allow it?

II What is a realistic timeline when a tiger wakes up and follows your path? How much will you accelerate your bring a man to the moon. With the tochnolog yof the $1960 \mathrm{~s}$, this was certainly not a realistic timeline. The energy transition is the easy part of climate change. More difficult will be the restauration of our biosphere and the reduction of the existing $\mathrm{CO}_{2}$ in the atmosphere. There is no guarantee that we will make it in time.

How can political implications and financial capitalism be set aside for an agreement on energy transition to be reached?

We can currently observe a sell-out of our natural resources, our biodiversity and our environment. Even
science and truth are bargained. All that are natural consequences of our ill-designed global conomic syster We need planetary thinking: economists that design a sustainable economy, politicians that stand for the benefit of the people and a young generation that refuses stupid pace? Mank Th was always able to cope with extraordinary 